\title{
Interactive comment on "Historic photographs of glaciers and glacial landforms from the R. S. Tarr collection at Cornell University" by Julie Elliott and Matthew E. Pritchard
}

Florence Fetterer (Referee)

fetterer@nsidc.org

Received and published: 31 August 2019

\section{General comments}

This is a well-presented description of a valuable collection of newly digitized photographs. The data set of digital images is accessible and reasonably well described with searchable metadata. With publication of this paper, the number of users of the photograph collection will increase, and increasing use is fundamental to preserving historical collections. 
This was a satisfying paper to read for several reasons. It is well written in plain language, it documents progress in preserving and promoting the use of important historical data, and it points to how archivists and geophysicists can collaborate. The paper lacks some detail on how metadata fields are chosen and how metadata is stored that would be helpful for those contemplating similar work.

Interactive

20-24: Various interest groups will be able to use the images for purposes beyond geophysical research. It's good to see that fact laid out clearly and prominently in these lines. The authors may want to reference Maness et al., 2017, doi:10.1016/j.grj.2017.10.002 because it stresses the importance of this kind of work through several examples, of which the NSIDC Glacier Photograph Collection is the most prominent.

45 ... A summary of the full collection is shown in Table 1...

It's not clear what the full collection referred to here is. It is the digitized collection of photographs, but those are part of a larger collection, and later it says

200 ... Due to budget constraints, we could not digitize all of the images, but focused on images of glaciers and glaciated landscapes from the Alaska and Greenland expeditions. There are still hundreds of other photographs in the RMC that were not digitized ...

Were all of the Alaska and Greenland expeditions photos digitized? Please clarify earlier in the manuscript (earlier than line 200) if this is so. "Collection" has a particular meaning in library archives, so referring to "full collection" can be confusing without some additional descriptive words.

48-58: Tables 2 and 3, with basic information on the photos in the digital collection, are really helpful for giving the reader a quick way to assess how useful the collection may be for their work. It is a good example for other collections to follow. NSIDCs Glacier Photograph Collection is too big to tabulate in exactly the same way, but we aspire to 
having searchable metadata that would allow such a table to be easily built.

186-187: ... Over a forty year period (including 20 years at Cornell), Tarr accumulated ESSDD images of glacial landforms ..

And he died at 48 ? This implies that he had been collecting photographs since he was 8 , which is certainly possible, but if so, it is so remarkable that it would be good to add some comment about it!

Section 3.1 on Original Material, lines 195-203: At NSIDC we have a similar situation. As of August 2018, the analog glacier photographs reside not at NSIDC, but in the University of Colorado at Boulder (CU) Library Archive. The Digital Library at CU and NSIDC collaborated on improving the digital portion of the collection, and both NSIDC and CU Library maintain interfaces to and identical copies of the digital portion of this large analog collection. These interfaces serve different user communities. The Background section of the User Guide, under https://nsidc.org/data/g00472, describes some of this and links to the CU Digital Library collection interface at https://cudl.colorado.edu/luna/servlet/CUB 12 12). At some point in the manuscript, it may be useful to link to the CU Library interface as well as to the NSIDC interface to the digital collection.

212-213: .... Master images were saved as 16B layered tiffs with curve adjustment layers. Uploaded access files are flattened, 8B, high quality compression, original sized jpegs. ...

Do the above lines mean that 16 bit images were digitally archived, but only 8 bit images are accessible/distributed? If so, perhaps some words on why 8 bit serve as well as 16 bit would be helpful.

221: Please list the range of file sizes, in $M B$, for the images, along with typical size.

224: Did you consider giving not only the entire collection but each individual photograph image a DOI?

Interactive

comment 
I found this section somewhat hard to follow. Adding some example filenames (e.g. "tve_lanternslide_0007.jpg" would help. Adding a listing of all the metadata fields that were used, along with the range of possible values for each field, would be good. It would also be good to make the metadata for the collection available as a downloadable spreadsheet. Was this considered? As it is, the only way I see of using the metadata is to make selections from the user interface. That's adequate for most users, but having the ability to download all metadata would be a great way to get a complete and detailed picture of the collection for those who want to go further.

Consider including a figure that is a screenshot of a page like this, https://digital.library.cornell.edu/catalog/ss:9417838, so that the discussed metadata fields are shown with a photograph, as it would appear to a data collection user.

259-265: ... In some cases, the envelope includes some "additional notes" that have not been included in the digital published metadata through the Cornell Library, but that are included in Table S1. For example, some images included a letter grade for the quality of the image $(A+$ being the highest and $D$ being the lowest), presumably assessed by Tarr or von Engeln. In some other images, these notes include the name of the photographer, or if the photograph is duplicated as a lantern slide set, the number of the lantern slide is given (see above). Table S1 also includes the appropriate USGS Quadrangle topographic map or Natural Resources Canada topographic map for the images when available....

This (above) is the first mention of Table S1. Please define it and put it in context. I am guessing it is a table of supplemental metadata. Is it accessible?

Lines 267 - 285: The detail is great, and it helps readers understand how complicated it can be to assign metadata consistently. But again, I had trouble following this section, and think a listing of all metadata fields, in a table with example rows, would help. 
283: "Twenty-four photographs from Martin's trips...". Searching now, I find 35 attributed to L. Martin, and 15 to an E.R. Martin, all from Alaska in the early 1900s.

Would you please cite the NSIDC collection somewhere in this section as "National Snow and Ice Data Center (2015)" and then have this, below, in the reference section?

National Snow and Ice Data Center (comp.). 2002, updated 2015. Glacier Photograph Collection, Boulder, Colorado USA. NSIDC: National Snow and Ice Data Center. doi: https://doi.org/10.7265/N5/NSIDC-GPC-2009-12. [Date Accessed].

294: I am happy to report that the NSIDC glacier photo collection now has more than 24,000 glaciers on line. More were digitized and described thanks to a grant to the $\mathrm{CU}$ Library (see Maness et al. 2017)

295 ...The NSIDC also holds and has scanned Martin's field notebooks from the 1904, 1905, and 1906 Alaska expeditions.

Are you able to give me a source or a link for the scanned Martin notebooks? NSIDC has not had an archivist for more than five years now, and I am not able to find the scans you reference. I believe the physical notebooks are safe with CU Library.

Finally, I agree with RC1, who writes "From you figures it shows that many of your images have already been geolocated - this information is not transferred to the metadata. I recommend that this location data is added to the metadata, or alternatively a supplementary file with image coordinates is attached to the manuscript. "

Technical corrections

28: correct typo and formatting in Hill et al.

102: think it needs a paragraph break after this line.

108: missing a close paren.

221: typo "originally size" 
Thank you for the opportunity to review this manuscript. It has been a pleasure.

Interactive comment on Earth Syst. Sci. Data Discuss., https://doi.org/10.5194/essd-2019-44, 2019.

Interactive

comment 